\title{
Do Sperm Really Compete and Do Eggs Ever Have a Choice? Adult Distribution and Gamete Mixing Influence Sexual Selection, Sexual Conflict, and the Evolution of Gamete Recognition Proteins in the Sea
}

\author{
Don R. Levitan* \\ Department of Biological Science, Florida State University, Tallahassee, Florida 32306 \\ Submitted December 21, 2016; Accepted July 21, 2017; Electronically published November 6, 2017 \\ Dryad data: http://dx.doi.org/10.5061/dryad.c57rf.
}

\begin{abstract}
The evolution of gametic compatibility and the effectiveness of compatibility, within and across species, depend on whether sperm from different males directly compete for an egg and whether eggs ever have a choice. Direct sperm competition and egg choice depend on whether sperm from different males arrive at an egg in the brief interval between first sperm contact and fertilization. Although this process may be relevant for all sexually reproducing organisms, it is most easily examined in aquatic external fertilizers. When sperm are released into the sea, packets of seawater at the spatial scale relevant to single eggs might contain sperm from only one male, eliminating the potential for direct sperm competition and egg choice. Field experiments and a simple heuristic model examining the degree of sperm mixing for the sea urchin Strongylocentrotus franciscanus indicate that degree of competitive fertilization depends on density and distribution of competing males and that the nature of this competition influences whether males with high- or low-affinity gamete recognition protein genotypes have higher reproductive success. These results provide a potential explanation for the generation and maintenance of variation in gamete recognition proteins and why effectiveness of conspecific sperm precedence can be density dependent.
\end{abstract}

Keywords: sperm competition, female choice, sexual selection, gamete recognition protein, sea urchin, fertilization.

\section{Introduction}

Male and sperm competition fuels sexual selection (Parker 1970; Andersson 1994), influences the possibility of female choice (Thornhill and Alcock 1983; Eberhard 1998), and

\footnotetext{
* E-mail: levitan@bio.fsu.edu.

ORCIDs: Levitan, http://orcid.org/0000-0001-5318-3312.
}

Am. Nat. 2018. Vol. 191, pp. 88-105. (C) 2017 by The University of Chicago. $0003-0147 / 2018 / 19101-57460 \$ 15.00$. All rights reserved. This work is licensed under a Creative Commons Attribution-NonCommercial 4.0 International License (CC BY-NC 4.0), which permits non-commercial reuse of the work with attribution. For commercial use, contact journalpermissions@press.uchicago.edu. DOI: $10.1086 / 694780$ under some circumstances drives the evolution of sexual dimorphism (Darwin 1871; Dunn et al. 2001). Although in many cases adult traits dictate who mates with whom, in a wide variety of taxa females mate with multiple males (chapters in Birkhead and Moller 1998) or release eggs into the environment during group spawning events where gamete interactions determine fertilization and mating success (Levitan and Ferrell 2006). In spite of the diverse array of organisms in which gamete interactions, either within the female or in the external environment, potentially influence mating success, we know very little about the actual dynamics of natural gamete interactions. This is because of the difficulty in observing gamete competition at the minute spatial scale at which these interactions occur.

In situations in which females retain eggs for internal fertilization or in which both sexes release gametes for external fertilization (broadcast spawning), there is ample evidence of multiple paternity (Birkhead and Moller 1998). However, the occurrence of multiple paternity does not necessarily imply gamete competition. Multiple paternity can occur because sperm from one male surround one subset of eggs, while another male's sperm surround another subset of eggs for reasons unrelated to sperm activity, such as adult behavior and morphology (McKinney et al. 1984; Birkhead 1998; Simmons and Siva-Jothy 1998), gamete dispersal via water movement (Coffroth and Lasker 1998), or pollen dispersal via air movement (Burczyk and Prat 1997). The advantages conferred by adult traits or environmental circumstances that might bias fertilization toward one or another male tend not be absolute (reviewed in Simmons and Siva-Jothy [1998] in insects and Birkhead and Moller [1992] in birds), suggesting that some degree of sperm competition may occur in spite of these adult morphological and behavioral traits. Traits such as sperm numbers (Gage and Morrow 2003), sperm size (Tourmente et al. 2011), velocity (Levitan 2000), chemotactic 
ability (Riffell et al. 2004), and compatibility (Levitan 2012) can influence the probability of fertilization and the winner in competition.

Interestingly, Parker (1998) adjusted his definition of sperm competition to better account for the dynamics of external fertilizers from "competition within a single female between sperm from two or more males for the fertilization of the ova" to "competition between the sperm from two or more males for the fertilization of a given set of ova" (p. 4). Although this broader definition provides a context for understanding male spawning strategies in broadcast spawners, it also obscures the important distinction between direct and indirect competition for an egg and how this might alter patterns of selection. A consequence of sperm directly or indirectly competing for access to individual eggs is that it can influence whether males and females are in conflict and whether eggs have the potential to choose among sperm. This can alter the outcome of selection on gamete traits and, in particular, the evolution of gamete recognition proteins. These dynamics can influence the effectiveness of conspecific sperm precedence in providing reproductive isolation across species and the evolution of variation in gamete recognition systems within species that influences reproductive success and thus potentially leads to speciation.

Conspecific sperm precedence (CSP) occurs when eggs can be fertilized by sperm of more than one species, but the affinity between conspecific sperm and eggs is greater than between heterospecific gametes (Howard 1999). Conspecific sperm precedence is thought to be an important mechanism driving reproduction isolation among closely related sympatric species or diverging populations (Howard 1999). Because conspecific and heterospecific sperm can fertilize eggs, CSP requires sperm from both species arriving at the egg simultaneously or within the brief interval between sperm contact and fusion. Once an egg is fertilized by earlier-arriving heterospecific sperm, the higher affinity of conspecific sperm is irrelevant; effective CSP depends on direct competition for eggs (competitive fertilization). Evidence of the context dependence of the effectiveness of CSP comes from laboratory assays indicating similar patterns of fertilization success between conspecific and heterospecific eggs in nochoice trials but strong evidence of fertilization bias toward conspecific fertilization when eggs have a choice of wellmixed conspecific and heterospecific sperm (Bierne et al. 2002; Willis et al. 2006). One explanation for the recent breakdown in reproductive isolation among some coral species hinges on the increasing likelihood of heterospecific sperm arriving to eggs prior to conspecific sperm as conspecific densities diminish (Fogarty et al. 2012b).

Variation in gamete affinities and recognition proteins also exists within a species, and this variation can influence reproductive success (Palumbi 1999; Levitan and Ferrell 2006; Levitan and Stapper 2010; Levitan 2012). Several hy- potheses have been offered to explain how intraspecific variation in these proteins can be maintained (Swanson and Vacquier 2002), as it is nonintuitive why proteins with lower gametic compatibility should be maintained in the population. Theory (Gavrilets 2000; Haygood 2004; Tomaiuolo and Levitan 2010) and empirical data (Levitan and Ferrell 2006; Levitan and Stapper 2010; Levitan 2012) support the notion that reduced compatibility would be favored when sperm are so abundant that high sperm-egg collision frequencies cause polyspermy and developmental failure. Under these high collision rate conditions, a mutation to the gamete recognition protein on the egg surface that reduces compatibility would reduce the risk of polyspermy and lead to higher reproductive success. When sperm from more than one male are well mixed, such that males directly compete for fertilizations (competitive fertilization), a mutation on the sperm protein that reduces compatibility would not be favored, because higher-affinity sperm will always win in direct competition even if it results in developmental failure; this translates into sexual conflict over optimal fertilization rates. Under these well-mixed conditions, polymorphism in the sperm protein only becomes beneficial if the variant sperm protein matches an established egg protein variant in the population. This scenario can produce a balanced polymorphism between matched sets of sperm and egg receptor proteins (Tomaiuolo and Levitan 2010).

However, if sperm from different males do not directly compete for single eggs (monogamous fertilization), sexual conflict is reduced, because both sexes suffer the cost of polyspermy. In this scenario, a sperm protein variant with lower affinities that reduces the risk of polyspermy can be favored. Monogamous fertilization releases the constraint that novel sperm proteins must match a particular egg protein; the mutant sperm merely needs to bind less efficiently to eggs compared to the resident sperm protein (Tomaiuolo and Levitan 2010). Thus, competitive fertilization selects for a precise match between the different sets of sperm and egg recognition loci, while monogamous fertilization can simply select for wimpy sperm that succeed because they are less compatible with available eggs and are less likely to result in polyspermy.

Finally, the nature of gamete interactions can also influence zygote production for two reasons. The first is that if there are not enough sperm (sperm limitation) or too much sperm (polyspermy), then zygote production will vary with sperm availability. But also, second, if an egg only has access to one male's sperm, then deficiencies in one male's ability to fertilize eggs cannot be compensated for by another male's success at fertilization. The degree of competitive or monogamous fertilization can influence whether selection is soft or hard (Wallace 1975).

For these reasons, the degree of competitive versus monogamous gamete interactions has a multitude of evolutionary consequences influencing the effectiveness of con- 
specific sperm precedence, the intensity of sexual conflict, and the hardness of selection.

The degree to which sperm from multiple males directly compete in external fertilizers is a function of the distribution, abundance, and timing of sperm release of males, the degree and nature of how released sperm stick together, and how released gametes mix in time and space as a function of water flow. Sperm - and eggs - can be released in viscous masses that form clumps or concentrated wisps that remain intact for some period before diffusing into the water column in nonpredicable ways as they interact with turbulent flow (reviewed in Crimaldi 2012). This sort of spatial heterogeneity could produce many parcels of seawater each containing high concentrations of sperm from one male. This heterogeneity could result in single eggs being exposed to only the sperm from single males, while different eggs released by the same female could be exposed to sperm from a different male or multiple males.

To determine whether sperm released into the ocean mix to the degree that sperm from different males would occupy the same tiny parcel of water that make up the local population of sperm influencing the fertilization of a single egg, I conducted a series of field experiments to determine the likelihood of competitive versus monogamous fertilization in the field and whether the winner of competition is determined by gamete recognition protein genotype. I present a simple heuristic model for how sperm availability and the degree of competitive fertilization can influence selection on gametic compatibility. I explore conditions where competitive fertilization is likely: group synchronous spawning. Group or aggregative spawning is common among broadcast spawning marine invertebrates and some fish species (reviewed in Levitan 1998b). Situations in which males and females pair spawn or situations in which asynchronies in spawning make sperm competition unlikely were not tested. The results provide some insight into the ecological and social interactions that dictate the likelihood of sexual conflict, the tempo and mode of selection on gamete traits, and the hardness of selection in broadcast spawning marine invertebrates. The sea urchin Strongylocentrotus franciscanus was used to test these ideas because of the ease with which individuals can be experimentally manipulated to investigate a range of spawning conditions that might influence the degree of sperm mixing and because of an established relation between fertilization and variation in the gamete recognition protein found on the sperm acrosome that binds to eggs, the sperm bindin protein.

\section{Methods}

The overall experimental design was to collect tiny droplets of seawater during a spawning event and determine the rel- ative abundance of sperm from different males that might interact with a single egg in these small water masses. The assay was to immediately expose a water droplet to a dense pool of unfertilized eggs to provide an enhanced opportunity for each spermatozoon in the collected water sample to find and fertilize an egg. These fertilized eggs developed into embryos that could be genotyped for paternity. This assay is not meant to estimate natural rates of fertilization in the sea (for estimates in this species, see Levitan 2002a); it is meant to assay the degree of sperm heterogeneity at small spatial scales to address the likelihood that sperm from different males have the opportunity to directly compete for fertilizations. The size of water droplet examined was generally $0.1 \mathrm{~mL}$. The volume of this sample, as a sphere, represents an approximately $2.7-\mathrm{mm}$ veneer of seawater surrounding the capture radius of an egg. Capture radius is defined by the size of the egg (Levitan 1993; Marshall et al. 2002), egg accessory structures (Farley and Levitan 2001; Podolsky 2002), and sperm chemotactic gradients (Riffell et al. 2004) produced by eggs. Sperm velocity in Strongylocentrotus franciscanus varies between 0.05 and $0.30 \mathrm{~mm} / \mathrm{s}$ (Levitan et al. 1991), and thus sperm are likely to interact, within seconds, to an egg within this water sphere. This sampling protocol approximates the spatial scale at which a local population of competing sperm might interact with a single egg. In 2016, experiments tested how reducing the seawater volume to $0.01 \mathrm{~mL}$, which represents an approximate $1-\mathrm{mm}$ veneer of water surrounding an egg, influences the estimate of sperm mixing.

Four field experiments were conducted during the springs of 2011, 2012, 2015, and 2016 in Barkley Sound, located on the west coast of Vancouver Island, British Columbia. The general protocol of these experiments used 1-mL syringes preloaded with $0.1 \mathrm{~mL}$ of concentrated unfertilized sea urchin eggs ( 10,000 eggs). These syringes were capped with a rubber tip and brought to the field. Male sea urchins were induced to spawn with an injection of $0.5 \mathrm{M} \mathrm{KCl}$ and then tagged with a numbered latex band stretched around each sea urchin. Ten minutes after the initiation of spawning, individual syringes were uncapped and a $0.1-\mathrm{mL}$ water sample was collected at a location determined by the particular experimental trial (fig. 1). The delay from male spawning to sample collection was to allow for sperm mixing and is justified by the observation that, during natural spawning events, males initiate spawning prior to females and continue to release sperm as females join in the spawning event (Levitan 2002a). After water sample collection, the syringes were immediately recapped and brought to the surface where the contents of the syringe were placed into $10 \mathrm{~mL}$ of filtered seawater. In 2016, paired experiments tested how $0.01-\mathrm{mL}$ volumes compared to $0.1-\mathrm{mL}$ volumes, using $1-\mathrm{mL}$ syringes altered by substituting a bolt and nut for the plunger. This modification allowed a half-turn of the screw to draw in a 


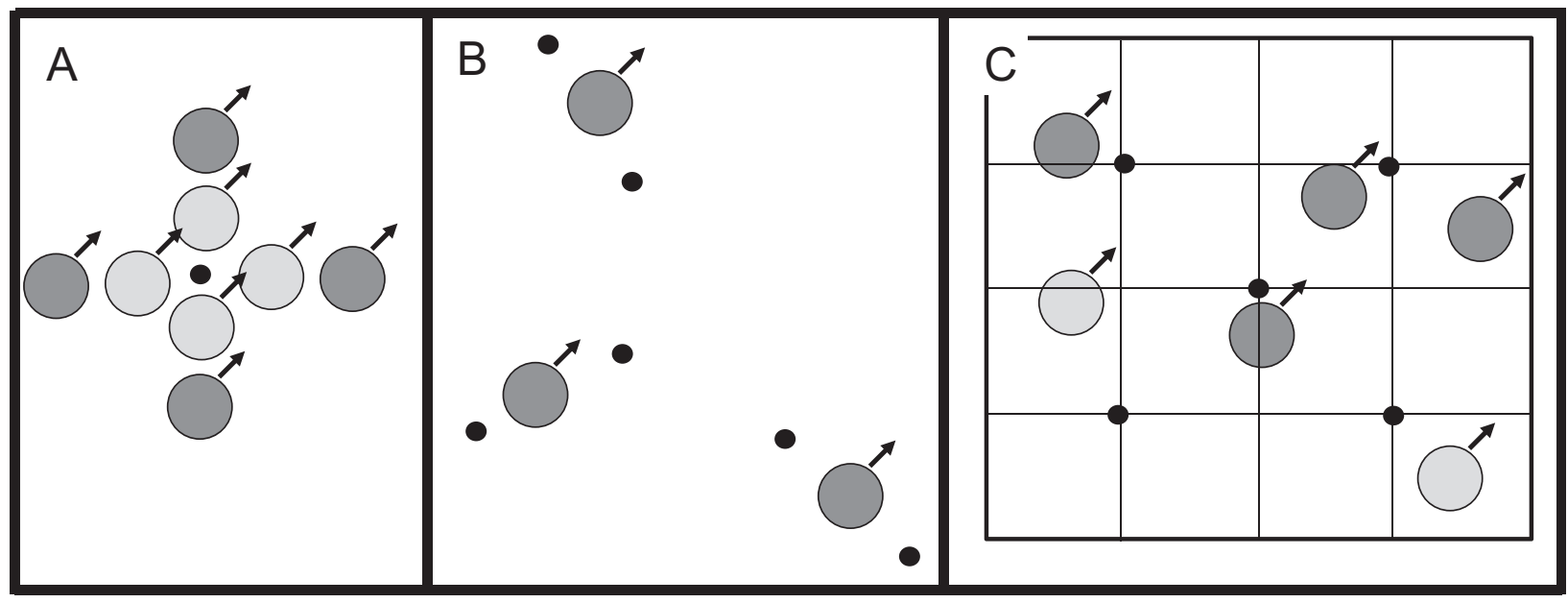

Figure 1: Experimental design for experiments 1-3. A, Experiment 1: males were placed 10 or $20 \mathrm{~cm}$ from the collection point. Six replicate syringe samples were taken at 30-s intervals. $B$, Experiment 2: males were placed haphazardly within $1 \mathrm{~m}^{2}$ and were allowed to wander for 10 min prior to sampling $10 \mathrm{~cm}$ toward the competing males or away from the competing males. $C$, Experiment 3: males were placed haphazardly at low (two males) or high (six males) density within a $1-\mathrm{m}^{2}$ quadrat, and samples were taken at five fixed points. Experiment 4 was identical to the $10-\mathrm{cm}$ treatment in $A$, with four $0.1-\mathrm{mL}$ and six $0.01-\mathrm{mL}$ seawater samples taken at 30 -s intervals.

0.01-mL water sample. For all syringe sampling, effort was made to collect a precise volume of water into the syringe and to move slowly and deliberately to minimize diver influence on water movement (kneeling position on bottom, slow arm and hand movements). Some error was likely in this regard but should not bias the results in any predictable manner.

For all experiments, tube feet-tissue samples were collected for genetic analysis from all sea urchins used. After $3 \mathrm{~h}$, all syringe samples were inspected for percentage of eggs fertilized, and then these samples were poured into $500 \mathrm{~mL}$ of filtered seawater to allow for larval development. After 3 days, approximately 50 larvae from each syringe sample were collected and placed in EtOH for paternity analysis. Paternity analysis was conducted on at least 10 larvae per syringe sample using microsatellite loci (for details of methods and analysis, see Levitan 2004). Paternity assignments were made using the program Cervus (Kalinowski et al. 2007). Because the sperm bindin gamete recognition protein genotype has been shown to influence paternity share (Levitan and Ferrell 2006; Levitan 2012), all males used in these experiments were sequenced for this gene after experiments were conducted.

Sperm bindin genotype was determined by sequencing the first of two exons in this gene (methods of DNA extraction, primers, polymerase chain reaction protocols, and haplotyping can be found in Levitan 2012). This first exon is known to be variable with two common nonsynonymous point substitutions leading to two frequent nonsynonymous haplotypes that have been shown to influence male reproductive success. The more common haplotype ( $60 \%$ fre- quency; Levitan 2012) is distinguished by having arginine (R) at amino acid site 13 and glycine (G) at amino acid site 35 (identified as the RG genotype). The second common haplotype has the reverse arrangement at these sites (GR, $\sim 30 \%$ frequency). Unpublished data indicate little intraspecific variation in the second exon in this gene. Prior research has determined that individuals with the RG allele outcompete individuals with the GR allele in direct competition; the GR protein has a lower average affinity to eggs and is less likely to cause polyspermy (Levitan 2012; D. R. Levitan, unpublished data).

The first experiment, conducted in 2011, involved placing spawning males in very close proximity to mimic extreme cases of intermale sperm competition and then at slightly more distant locations to look at reduced crowding effects. This experiment determined the degree of multiple paternity within a syringe, the total multiple paternity across syringes, and the degree to which different males dominated paternity share across 30-s sampling intervals. In this experiment, four spawning male sea urchins were placed in a square, $10 \mathrm{~cm}$ from a central point. Sea urchin positions were maintained by using a 1-m PVC pipe and blocking the sea urchins if they attempted to move. These sea urchins are large, with a test diameter of $10-15 \mathrm{~cm}$ and a spine canopy that doubles this size. It would be difficult to pack more individuals into this space without piling them on top of each other. At the center of this array, six syringe samples were taken at 30-s intervals. Then the spawning males were moved outward to $20 \mathrm{~cm}$ from the central point, and 2 min later an additional six samples were collected from this central point. Sea urchins were mapped for their orientation within the 
trial. This experiment was replicated five times with unique sea urchins. Because not all syringes produced larvae, four syringes were selected for paternity analysis per replicate.

Water flow was monitored during these experiments with an InterOcean S4 current meter recording depth, water velocity, and direction every $0.5 \mathrm{~s}$. Two measures of water velocity were calculated: surge velocity is the average velocity calculated every $0.5 \mathrm{~s}$; advection is the average velocity calculated as the straight-line distance water moved over the course of the experiment divided by the length of time of the experiment. Surge velocity reveals short-term velocity and can be related to turbulence and mixing, while advection provides information on the residence time of sperm over the spawning individuals and syringes.

The second experiment, conducted in 2012, examined how more random spatial relations among three male sea urchins influenced the degree of intermale competition at these small spatial scales. In this experiment, three males, induced to spawn via $\mathrm{KCl}$ injection, were placed next to a central marker. These sea urchins were allowed to roam freely for $10 \mathrm{~min}$, and then one syringe sample was taken $10 \mathrm{~cm}$ from each focal male in a location closest to the other two sea urchins (toward the central point of the triangle defined by the three sea urchins) and a second sample was taken $10 \mathrm{~cm}$ from the focal sea urchin in the opposite direction away from the other males. All three males were sampled in this manner for a total of six samples per replicate. Immediately following water sampling, the positions of all spawning males were mapped. Ten replicates of this experiment were conducted using unique sea urchins. Water flow was monitored as noted above.

The third experiment, conducted in 2015, allowed not only male movement but also a nonfixed distance between spawning males and the sampling of eggs to represent varying distances between males and females. Two spawning densities were examined, two and six males per square meter, in which males were randomly placed into a $1-\mathrm{m}^{2}$ quadrat and allowed to move within this arena, and water samples were collected at five fixed points within the quadrat - in the center and halfway between the center and the four corners of the quadrat (fig. 1). Immediately after collection of water samples, the location of the sea urchins within the quadrat was mapped. Water flow was monitored as above, and eight replicates of this experiment were conducted over a range of flow conditions.

The fourth experiment, conducted in 2016, examined whether smaller water droplets $(0.01 \mathrm{~mL})$ influenced the estimates of the likelihood of competitive fertilization. The placement of males was similar to the $10-\mathrm{cm}$ distance in the first experiment. Four males were induced to spawn and placed $10 \mathrm{~cm}$ from a central point. For each replicate, $10 \mathrm{sy}-$ ringe samples were taken in the following order: two $0.1-\mathrm{mL}$ samples, six 0.01-mL samples, and two final 0.1-mL samples.
More 0.01-mL samples were taken because of the expected lower fertilization rates in these very small volumes of collected seawater and the expected lower number of embryos produced. For each replicate, two $0.1-\mathrm{mL}$ samples and two $0.01-\mathrm{mL}$ samples were analyzed for paternity. Seven replicates of this experiment were conducted.

\section{Simulation Model}

A simple model was used to examine how the degree of sperm availability and the degree of competitive versus noncompetitive fertilization events among males would select for either high- or low-affinity sperm. Fertilization kinetics were predicted using the model by Styan (1998), which allows for fertilization failure caused by polyspermy. An alternate fertilization kinetic model (Millar and Anderson 2003) produced similar estimates of fertilization under the parameter values used here (their fig. $1 B$ ). The Styan model estimates successful fertilization (the fraction of eggs fertilized by only one spermatozoon) as a function of sperm $\left(S_{0}\right)$ and egg $\left(E_{0}\right)$ concentration, the collision constant $\left(\beta_{0}\right)$, the efficiency of collisions to fertilizations $\left(F_{\mathrm{e}}\right)$, the time period of sperm and egg interaction $(t)$, and the time it takes an egg to erect a successful block to polyspermy $\left(t_{\mathrm{b}}\right)$.

$$
\begin{aligned}
& \text { Monospermic fertilization } \\
& \qquad=1-\mathrm{e}^{-x}-\left(1-\mathrm{e}^{-x}-x \mathrm{e}^{-x}\right)\left(1-\mathrm{e}^{-b}\right)
\end{aligned}
$$

(Styan 1998, eq. [16]), with

$$
x=F_{\mathrm{e}} \frac{S_{0}}{E_{0}}\left(1-\mathrm{e}^{-\beta_{0} E_{0} \tau}\right)
$$

(Styan 1998, eq. [5]) and

$$
b=F_{\mathrm{e}} \frac{S_{0}}{E_{0}}\left(1-\mathrm{e}^{-\beta_{0} E_{0} t_{b}}\right)
$$

(Styan 1998, eq. [13]). In these equations, $x$ is the average number of potential fertilizers per egg, and $b$ is the average number of extra fertilizing sperm contacting an egg following the first successful collision and prior to the time period needed for establishment of a block to polyspermy $\left(t_{\mathrm{b}}\right)$. To estimate the fraction of eggs fertilized by two competing males with different compatibilities $\left(F_{\mathrm{e}}\right)$, I summed the number of potential fertilizing sperm per egg for each male based on his compatibility for the calculation of both $x$ and $b$.

I held egg concentration $(1 / \mu \mathrm{L})$, sperm-egg contact time (100 s), the time to erect a polyspermy block (1 s), and the collision constant $\left(0.002 \mathrm{~mm}^{3} / \mathrm{s}\right)$ fixed and varied sperm concentration and the collision efficiency (compatibility). Sperm concentration varied from a low of $50 \mathrm{sperm} / \mu \mathrm{L}$ and then increased in concentration in subsequent iterations by $50 \%$ for 23 increments. For compatibility, the lowaffinity male was fixed at a collision efficiency of 0.025 
( $2.5 \%$ of collisions resulting in a fertilizable collision), while the higher-affinity male varied from 0.03125 to 0.1 , or a $25 \%-$ $400 \%$ affinity advantage. This range in collision efficiencies coincides with published values (Levitan et al. 1991). Estimates of successful fertilization were calculated in the absence and presence of a competing male that differed in compatibility. For simplicity, the relative abundance of sperm from the two males was fixed at $1: 1$.

The fertilization success of males out of competition was based on the sperm concentration and the fertilization efficiency of each male. The fertilization of each male in competition was calculated as the total fraction of eggs fertilized (as described above) divided among the two males, based on the compatibility difference between the males (e.g., a $\times 3$ compatibility difference resulted in a $25 / 75$ paternity split, as in Tomaoulo and Levitan 2010). For each condition (level of sperm concentration and compatibility difference), the simulations examined 101 scenarios of the degree of competition ( 0 events in competition, 100 out of competition . . . 100 events in competition, 0 events out of competition). The summed success of each male in and out of competition was calculated for each scenario, and the male with the higher overall success was declared to have higher reproductive success. For each run, the degree of competition at which there was a transition of which male (affinity type) won was reported. All data and code used in this study were deposited in the Dryad Digital Repository: http://dx.doi.org/10.5061 /dryad.c57rf (Levitan 2017).

\section{Results}

\section{Experiment 1: Symmetrical Distances among Males at High and Very High Densities}

In the first experiment, sea urchins were constrained to spawn at either 10 or $20 \mathrm{~cm}$ from the collection point or $20-40 \mathrm{~cm}$ from each other, which is equivalent to 64 or $16 \mathrm{males} / \mathrm{m}^{2}$. Given a 1:1 sex ratio, this would translate into experiments that mirror natural populations at extremely high densities (32-128 individuals $/ \mathrm{m}^{2}$ ). Although at the $\mathrm{m}^{2}$ scale this would translate into unusually high densities, finding 4 individuals $/ 0.25 \mathrm{~m}^{2}$ with nearest-neighbor distances of $10-20 \mathrm{~cm}$ is fairly typical of natural conditions in Barkley Sound, British Columbia (Levitan 2002a). Fertilization success in this experiment varied between 0 and $100 \%$, with an average percentage of fertilization of $32.28 \%$ (SE $=7.1 \%, n=20)$ and $18.8 \%(\mathrm{SE}=5.6 \%, n=20)$ for the 10 - and $20-\mathrm{cm}$ trials, respectively. This estimate of fertilization is lower than prior studies (Levitan 2002a, 2004), likely because of the small volume of seawater containing sperm that was introduced to an extremely dense suspension of eggs, thus shifting the sperm to egg ratio. This was the anticipated consequence of attempting to generate a large total number of embryos as opposed to a high percentage of fertilized eggs. Because some of the lab cultures failed to produce sufficient larvae for paternity analysis, four syringe samples from each replicate (four at $10 \mathrm{~cm}$ and four at $20 \mathrm{~cm}$ ) were analyzed for paternity to maintain a balanced design. The average paternity share of the paternity winner, per syringe, was $63.7 \%$ $(\mathrm{SE}=4 \%, n=20)$ and $69.3 \%(\mathrm{SE}=3 \%, n=20)$ for the 10- and $20-\mathrm{cm}$ trials; increased crowding led to a more equal paternity distribution (fig. $2 A, 2 B$ ). To examine the factors that influenced the paternity share of the winning male, I used a general linear model testing the number of larvae sired by the dominant male as a function of the main effect of level of crowding and covariates of advection, surge velocity, the timing of when the sample was taken (first through fourth time interval), the proportion of eggs fertilized in a syringe (arcsine transformed), and the total number of larvae genotyped. Overall, paternity share dominance increased at the lower level of crowding, and there were significant interactions of crowding with surge velocity, advection, and fertilization (table 1). The sequence of when the sample was taken did not influence paternity share; there was no indication that sperm mixing among males increased (or decreased) over these time intervals. To examine the significant interactions, I conducted independent analysis at each level of crowding. At the high level of crowding, increased surge and decreased advection was associated with increased paternity dominance. At the lower level of crowding, increased fertilization in the syringe was associated with increased paternity dominance (table 1).

Within a replicate spawning event, which male garnered the highest paternity share varied among the four syringe samples, sampled in the same location, but at 30-s intervals. On average, the overall best male won the highest paternity share $65 \%$ ( $\mathrm{SE}=12.7 \%, n=20)$ and $80 \%$ (SE $=5.0 \%$, $n=20)$ of the time for the 10 - and $20-\mathrm{cm}$ trials, respectively. At both levels of crowding, within a syringe, an average of $30 \%$ of males had zero paternity, but when pooled across all four syringe samples, all males had at least some paternity share. Only two syringes, one from each level of crowding, had single males winning all fertilizations (monogamous fertilization).

Overall, an increase in distance among males and to the collection point resulted in increased dominance by single males, and at lower levels of crowding, increased fertilization in the syringe was associated with higher dominance. In spite of these significant but subtle differences in paternity share, the striking result is that at both levels of crowding, there was almost always (158 out of 160 syringes) some degree of sperm from multiple males detected within a single droplet of water; the potential for intermale competition was noted in $99 \%$ of these small water droplets.

The effect of male sperm bindin genotype on paternity shares was tested using RG and GR homozygous and RG/GR 

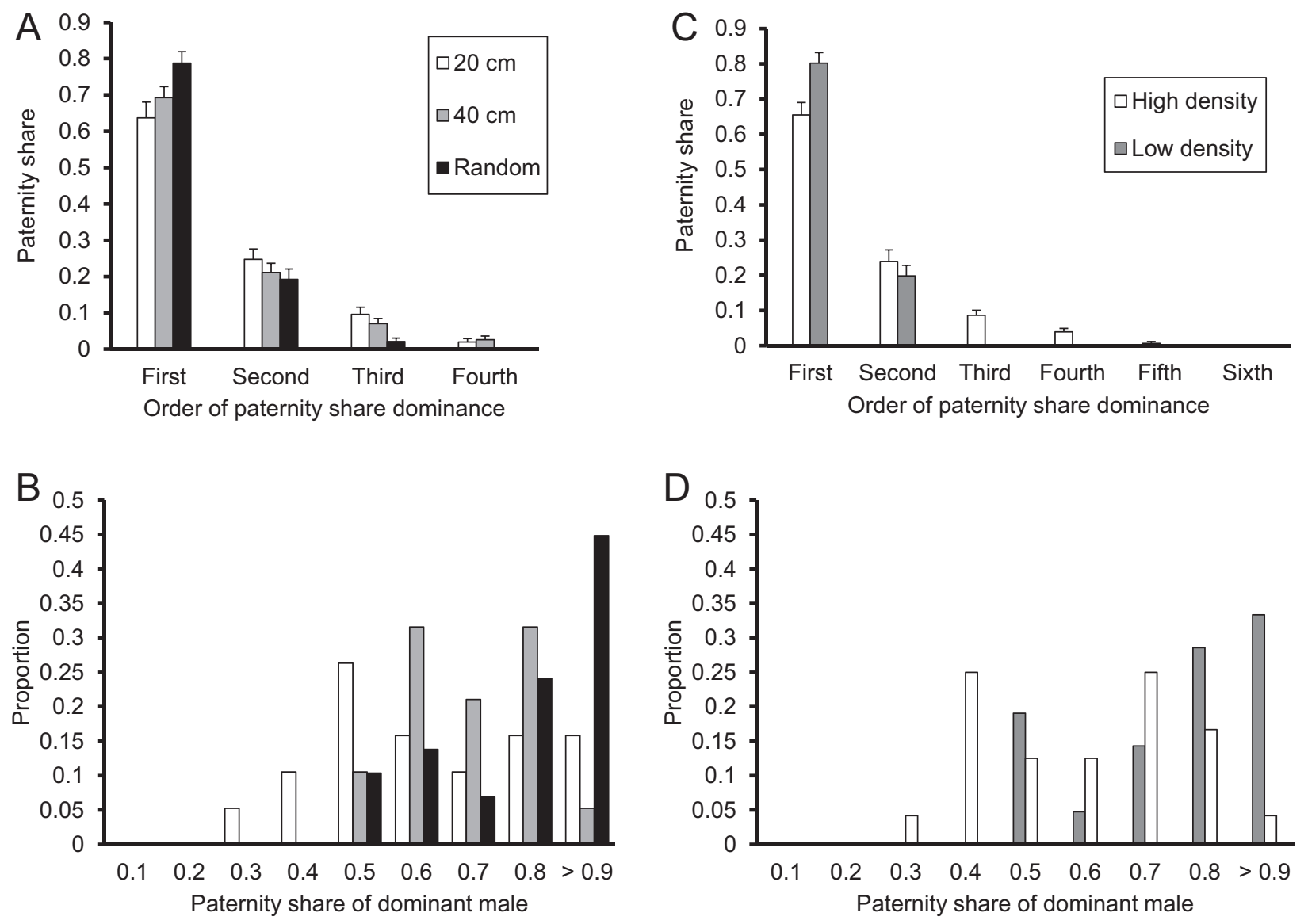

Figure 2: Distribution of paternity share for experiments 1 and $2(A, B)$ and experiment $3(C, D)$. Top panels, paternity share of each male ranked from highest to lowest paternity share; most males garnered some paternity share. Bottom panels, distribution of paternity share for the paternity winner in each trial; the ability of the paternity share winner to dominate paternity increased with distance between males and decreased with density.

heterozygous males and excluded the $5 \%$ of instances in which the male had a rare (GG) allele (5\% of cases). I used a general linear model testing the number of larvae sired by a male as a function of level of crowding (10- or $20-\mathrm{cm}$ trials) and sperm bindin genotype (RG, GR, or heterozygote) as main effects and the fraction of eggs fertilized in a syringe (arcsine transformed) and the total number of larvae sired across all males as covariates, plus two- and three-way interactions. Because there was a significant interaction between level of crowding and genotype $(P=.019)$, independent tests were made at each level of crowding. At the low level of crowding, there was no significant effect of sperm bindin $(P=.85)$ or of the interaction of sperm bindin and fertilization $(P=.70)$. The main effect of sperm bindin and the interaction of sperm bindin and fertilization was significant at the high level of crowding (table 2). To examine this interaction, the data was separated into the categories of low and high fertilization (clear break in data at $40 \%$ ) and tested with a similar general linear model testing the number of larvae sired as a function of sperm bindin and the total number of larvae sired across all males. At the high level of fertilization, sperm bindin was not significant $(P=.17)$ but was significant at the low level of fertilization $(P=.0071)$. At this low level of fertilization, RG homozygous genotypes had significantly higher paternal success than RG/GR heterozygotes (paternity share of $36 \%$ vs. $9 \%, P=.0018)$. Although homozygous RG genotypes obtained a nonsignificant higher paternity compared with homozygous GR individuals (20\% paternity share), the loweraffinity GR genotypes were by far the rarest genotype (only three GR homozygous males) and did not provide a powerful pairwise test with other genotypes. Sperm bindin genotype influenced paternity when males were in close proximity to each other and when fertilization was lower. High levels of fertilization may signal a syringe that was swamped by a wisp of sperm from a single male that would diminish the ability of sperm genotype to influence paternity share. 
Table 1: Experiment 1: general linear model of paternity share of winning male (number of larvae sired by winning male) across two levels of crowding (10 and $20 \mathrm{~cm}$ from seawater sampling), with surge velocity, advection, the time sequence of sample collection, the fertilization in the syringe (arcsine transformed), and the total number of larvae genotyped as covariates

\begin{tabular}{lrrrrr}
\hline & df & Type III SS & MS & $F$ & Pr $>F$ \\
\hline Source: & & & & & \\
$\quad$ Crowding & 1 & 1.87 & 1.87 & 1.17 & .2890 \\
Surge & 1 & 9.48 & 9.48 & 5.92 & .0213 \\
Advection & 1 & 2.31 & 2.31 & 1.45 & .2390 \\
Total larvae & 1 & .32 & .32 & .20 & .6564 \\
Arcfert & 1 & 8.79 & 8.79 & 5.49 & .0262 \\
Time & 1 & .52 & .52 & .32 & .5731 \\
Surge $\times$ crowding & 1 & 10.32 & 10.32 & 6.45 & .0167 \\
Advection $\times$ crowding & 1 & 9.52 & 9.52 & 5.95 & .0211 \\
Arcfert $\times$ crowding & 1 & 8.67 & 8.67 & 5.42 & .0271 \\
Time $\times$ crowding & 1 & .37 & .37 & .23 & .6327 \\
Error & 29 & 46.40 & 1.60 & & \\
$\quad$ Corrected total & 39 & 109.78 & & & \\
High crowding source: & & & & & .0029 \\
Surge & 1 & 20.90 & 20.90 & 12.35 & .0203 \\
Advection & 1 & 11.22 & 11.22 & 6.63 & .6048 \\
Arcfert & 1 & .47 & .47 & .28 & \\
Error & 16 & 27.08 & 1.69 & & .0020 \\
$\quad$ Corrected total & 19 & 64.20 & & & \\
Low crowding source: & & & & & \\
$\quad$ Surge & 1 & .05 & .05 & .04 & .2691 \\
Advection & 1 & 1.71 & 1.71 & 1.31 & \\
Arcfert & 1 & 17.73 & 17.73 & 13.55 & .0020 \\
Error & 16 & 20.93 & 1.31 & & \\
$\quad$ Corrected total & 19 & 44.95 & & & \\
\hline Note Becaus of & & & & & \\
\hline
\end{tabular}

Note: Because of the significant interactions with crowding, independent tests were conducted at each level of crowding with the nonsignificant effects of timing and total number of larvae removed. At high crowding, water flow influenced paternity dominance; at low crowding, the level of fertilization influenced paternity dominance. Sums of squares (SS) and mean squares (MS) are reported.

\section{Experiment 2: Asymmetrical Distances among Males at Moderate Densities}

In the second experiment, in which sea urchins were unconstrained and were allowed to move, the closest male competitor to a focal male averaged $75 \mathrm{~cm}(\mathrm{SE}=8 \mathrm{~cm}$, $n=30$ ) and ranged from 10 to $169 \mathrm{~cm}$. This range in nearest-neighbor distances is similar to the natural range $(10-300 \mathrm{~cm})$ noted from 29 sites in Barkley Sound that ranged in population density from 0.1 to $10 / \mathrm{m}^{2}$ (Levitan $2002 a, 2004)$. The average density in this experiment, calculated based on the area of a circle defined by the diameter from the most distant males in each trial, was $2.1 \mathrm{males} / \mathrm{m}^{2}$ ( $\mathrm{SE}=0.44, n=10$ trials). Fertilization success including the syringes closer to and further from the competing males ( $n=2$ syringes per male) varied between 0 and $95 \%$ (average $19.3 \%$, SE $3.1 \%, n=60$ ). The average paternity share of the focal male was $78.7 \%(\mathrm{SE}=3.2 \%, n=30$ males; fig. $2 A, 2 B$ ), with a null expectation of $33 \%$ among three spawning males. I used a general linear model testing the number of larvae sired by the focal male with the main effect of sample location (closer to or farther from competitors) with the fraction of eggs fertilized in a syringe (arcsine transformed), distance to the nearest competitor, water advection, and the total number of larva sired across all males as covariates and the interaction of male competitor distance and fertilization in a syringe. The analysis revealed a significant effect of fertilization and a marginally significant effect of the distance to the nearest male (table 3; fig. $3 A, 3 B$ ). Similar to findings in experiment 1 , paternity share of the focal male increased with increasing proportion of eggs fertilized within a syringe (fig. $3 A$ ). In addition, paternity share increased with the distance of the nearest male competitor to the focal male (fig. $3 B$ ).

Examining only whether the syringe was completely dominated by a single male (monogamous) compared to syringes with fertilization by multiple males indicated that the likelihood that a syringe was monopolized by a single male was significantly influenced by the degree to which eggs were fertilized and the distance to the nearest competing male. 
Table 2: Experiment 1: general linear model of paternity share of each male (number of larvae sired by male) across two levels of crowding $(10$ and $20 \mathrm{~cm}$ ) and three levels of sperm bindin genotype (RG/RG, RG/GR, and GR/GR), with the fraction of eggs fertilized (arcsine transformed) and the total number of larvae sired across all males as covariates, along with all two- and three-way interactions

\begin{tabular}{|c|c|c|c|c|c|}
\hline & $\mathrm{df}$ & Type III SS & MS & $F$ & $\operatorname{Pr}>F$ \\
\hline \multicolumn{6}{|l|}{ Source: } \\
\hline Crowding & 1 & .09 & .09 & .01 & .9053 \\
\hline Sperm bindin & 2 & 65.66 & 32.83 & 4.96 & .0083 \\
\hline Arcfert & 1 & .59 & .59 & .09 & .7659 \\
\hline Total larvae & 1 & .48 & .48 & .07 & .7888 \\
\hline Crowd $\times$ bindin & 2 & 53.79 & 26.90 & 4.07 & .0192 \\
\hline Arcfert $\times$ bindin & 2 & 67.07 & 33.54 & 5.07 & .0075 \\
\hline Crowd $\times$ arcfert & 1 & .09 & .09 & .01 & .9082 \\
\hline Crowd $\times$ bindin $\times$ arcfert & 2 & 22.85 & 11.43 & 1.73 & .1815 \\
\hline Error & 138 & 912.67 & 6.61 & & \\
\hline Corrected total & 151 & $1,054.84$ & & & \\
\hline \multicolumn{6}{|l|}{ High crowding source: } \\
\hline Sperm bindin & 2 & 115.21 & 57.60 & 11.13 & $<.0001$ \\
\hline Arcfert & 1 & .64 & .64 & .12 & .7271 \\
\hline Total larvae & 1 & .84 & .84 & .16 & .689 \\
\hline Arcfert $\times$ bindin & 2 & 104.69 & 52.35 & 10.12 & .0001 \\
\hline Error & 69 & 357.04 & 5.17 & & \\
\hline Corrected total & 75 & 494.78 & & & \\
\hline \multicolumn{6}{|c|}{ Low fertilization, high crowding source: } \\
\hline Sperm bindin & 2 & 68.28 & 34.14 & 5.55 & .0071 \\
\hline Total larvae & 1 & .21 & .21 & .03 & .8529 \\
\hline Error & 44 & 270.82 & 6.16 & & \\
\hline Corrected total & 47 & 339.31 & & & \\
\hline
\end{tabular}

Note: Measures of water flow were excluded because preliminary analysis did not find these factors significant. Because of significant interactions with crowding, independent tests were conducted at each level of crowding. At the low level of crowding, there was no significant main effect of genotype $(P=.85)$ or the interaction of genotype with fertilization $(P=.70)$. These factors were significant at high levels of crowding. To explore the genotype by fertilization interaction at high crowding, the data were divided into high- and low-fertilization categories and tested for the effect of sperm bindin genotype. Sums of squares (SS) and mean squares (MS) are reported.

This was tested using an $\mathrm{R} \times \mathrm{C}$ G-test examining the number of syringes with either single or multiple sires as a function of close or far competitors ( $>1 \mathrm{~m}$ or $<1 \mathrm{~m}$ ) and high and low fertilization $(>40 \%$ or $<40 \%, G=12.61$, $\mathrm{df}=3, P<.01$ ). Overall, $73 \%$ of syringes in this experiment were fertilized by multiple males, compared to $99 \%$ in experiment 1 . Single males always monopolized syringes when fertilization was above $40 \%$ and competitors were further than $1 \mathrm{~m}$ away, whereas single males rarely monopolized syringes when competitors were closer and fertilization was lower (fig. 3C). Un-

Table 3: Experiment 2: general linear model of paternity share of the focal male (number of larvae sired by male) as a function of the fraction of eggs fertilized in the syringe (arcsine transformed), distance to the nearest male competitor, location of syringe sampling, water advection, and the total number of larvae sired by all males in a syringe as covariates, plus the interaction of fertilization and the distance to the nearest male competitor

\begin{tabular}{lrcrrc}
\hline Source & df & Type III SS & MS & $F$ & Pr $>F$ \\
\hline Arcfert & 1 & 35.90 & 35.90 & 4.35 & .0423 \\
Competitor & 1 & 28.81 & 28.81 & 3.49 & .0677 \\
Location & 1 & 1.84 & 1.84 & .22 & .639 \\
Advection & 1 & 3.52 & 3.52 & .43 & .5171 \\
Total larvae & 1 & 1.67 & 1.67 & .20 & .6546 \\
Arcfert $\times$ competitor & 1 & 8.91 & 8.91 & 1.08 & .304 \\
Error & 49 & 404.52 & 8.26 & & \\
$\quad$ Corrected total & 55 & 502.98 & & & \\
\hline
\end{tabular}

Note: The sperm bindin genotype of the focal male was added to this model and found to be not significant (main effect of genotype $P=.3267$ ). Sums of squares (SS) and mean squares (MS) are reported. 

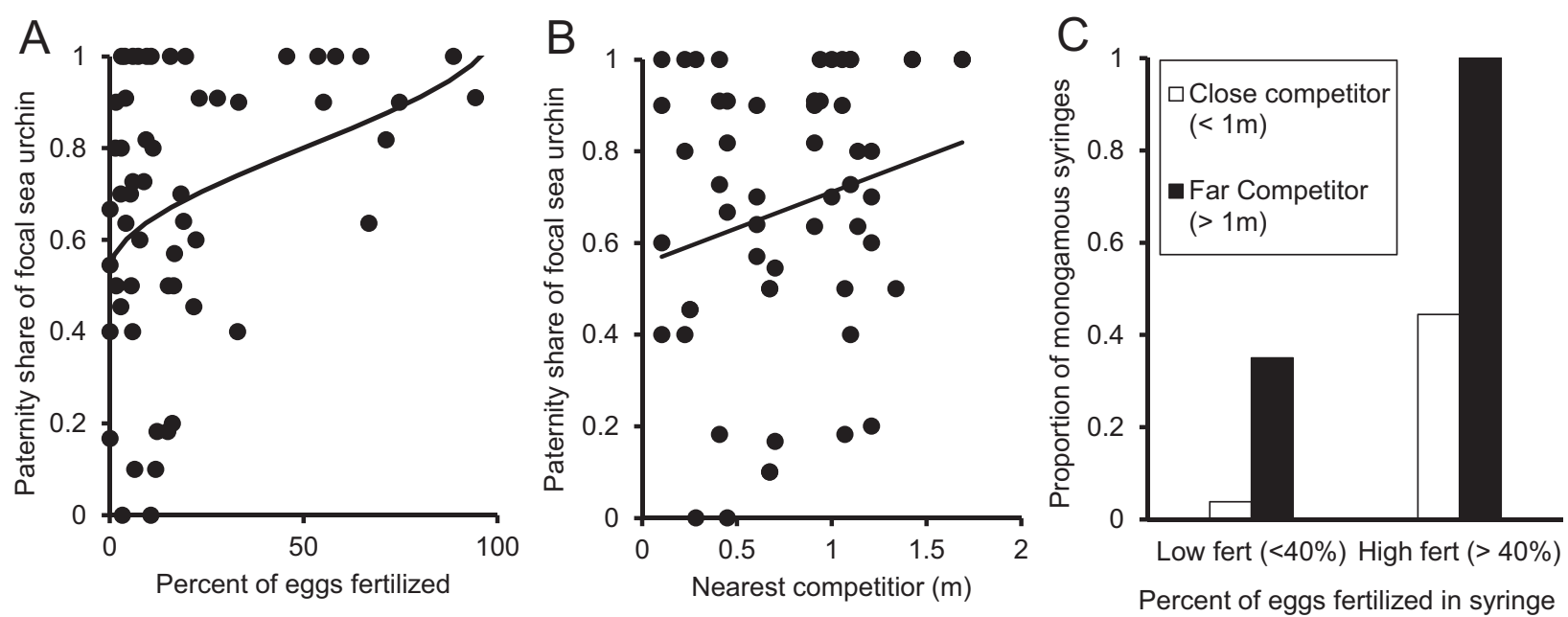

Figure 3: Paternity share of the focal male in experiment 3 as a function of the percentage of eggs fertilized in syringe, back transformed from arcsine fertilization $(A)$ and the distance to the nearest competitor $(B)$. The focal male's ability to dominate paternity increased with the fraction of eggs fertilized and the distance to the nearest competitor. $C$, Proportion of syringes that were completely dominated by the focal male (monogamous fertilization) as a function of the percentage of eggs fertilized and distance to the nearest competitor. Monogamous fertilizations were ubiquitous when competitors were greater than $1 \mathrm{~m}$ away and fertilization exceeded $40 \%$, and vice versa for competitive fertilization events.

like the first experiment, in which males were equally distant to eggs, unevenly positioned males often monopolized single droplets of seawater.

Including the sperm bindin genotype into the analysis described in table 3 yielded a nonsignificant effect of male genotype on the success of the focal male $(P=.33$ for main effect of sperm bindin genotype); although the pattern of mean paternity share of the focal male remained as predicted from prior work of RG/RG homozygous males $(71 \%, \mathrm{SE}=6 \%, n=19)$, followed by RG/GR heterozygous males $(62 \%, \mathrm{SE}=6 \%, n=21)$ and then GR/GR homozygous males $(59 \%, \mathrm{SE}=14 \%, n=4)$, these trends were not significant. When individuals were more distant and asymmetrically located, the effect of the sperm bindin genotype on the ability to monopolize fertilization events was reduced.

\section{Experiment 3: Variable Distances among Males and Eggs at Moderate to High Densities}

In the third experiment, the distance between the spawning male and the collection point of the water sample was variable and generally farther (mean $27 \mathrm{~cm}$, range $2-58 \mathrm{~cm}$ at 2 males $/ \mathrm{m}^{2}$; mean $16 \mathrm{~cm}$, range $1-45 \mathrm{~cm}$ at 6 males $/ \mathrm{m}^{2}$ ) than in the prior two experiments in which this point was fixed and close to the male. These greater distances resulted in much lower levels of overall fertilization success per syringe (mean $1.4 \%$, range $0-8.7 \%$ at 2 males $/ \mathrm{m}^{2}$; mean $2.4 \%$, range $0-12.3 \%$ at 6 males $\left./ \mathrm{m}^{2}\right)$. At the higher density, only 1 of 24 total syringes was completely monopolized by a single male (4\%), while two syringes were completely monopolized at the lower density (10\%). The distribution of paternity was similar to prior experiments (fig. $2 \mathrm{C}$, $2 D$ ), with the dominant male at the higher-density treatment obtaining an average of $65.5 \%(\mathrm{SE}=3.6 \%, n=24)$ of the paternity, while at lower density, this increased to $80.2 \%$ ( $\mathrm{SE}=3.0 \%, n=20)$. At high density, as many as five (of the six) males contributed to the paternity in single water droplets (in $8 \%$ of syringes; fig. $4 A$ ). At low density, $90 \%$ of droplets had contribution from both males.

The effect of sperm bindin genotype was only significant at the higher density of 6 males $/ \mathrm{m}^{2}$. A general linear model testing the number of larvae sired by each male with the main effect of sperm bindin genotype (RG/RG, RG/GR, and GR/GR), using the distance of the male to the syringe, the fraction of eggs fertilized in a syringe (arcsine transformed), and the total number of larvae sired across all males in a syringe as the covariates and the interaction of sperm bindin genotype and distance to a syringe as an interaction, revealed a significant effect of sperm bindin genotype and distance with a marginal interaction of these factors (table 4). As in prior experiments, the high-affinity RG/RG ( $n=55$ crosses) males had the highest success, followed by RG/GR (60 crosses) and GR/GR individuals ( 5 crosses). The latter two genotypes had similar success, and again the rarer GR/GR genotypes had low sample size and weak statistical power to distinguish them among other genotypes (fig. 4). At the lower-density treatment, neither the main effect of sperm bindin genotype $(P=.62)$ or the interaction of genotype with distance $(P=.42)$ were significant. 

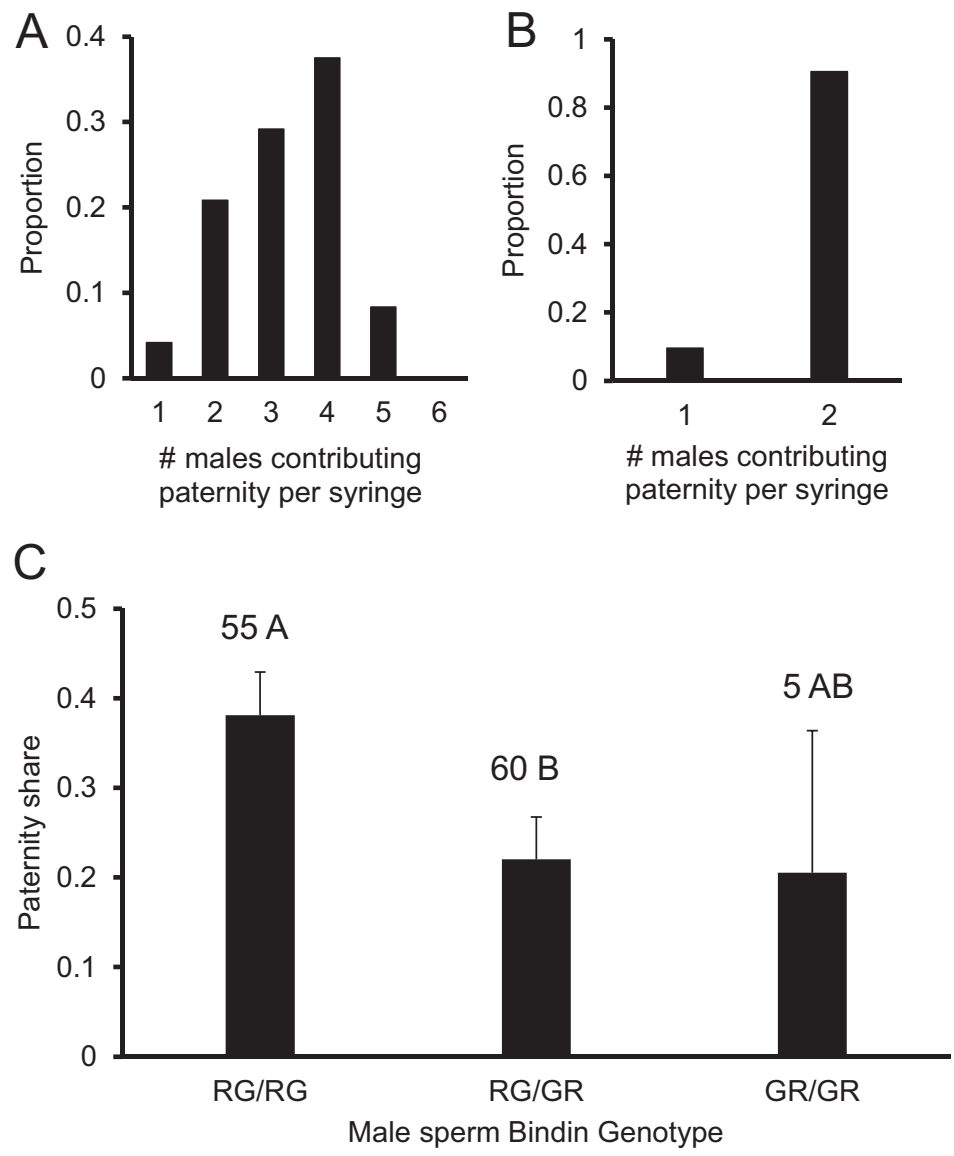

Figure 4: Patterns of paternity in the high-density $(A)$ and low-density $(B)$ treatments of experiment 3 . Sperm bindin genotype significantly contributed to the paternity share in the high-density treatment $(C)$. Numbers indicate sample sizes; unique letters indicate significant pairwise differences in means.

\section{Experiment 4: Testing Whether Reducing the Sampled Seawater Volume Influences Estimates of Sperm Mixing}

In the fourth experiment, there was a trend toward an increase in the paternity share of the dominant male in the $0.01-\mathrm{mL}$ droplet $(74.8 \%, \mathrm{SE}=4.7, n=14)$ compared to the $0.1-\mathrm{mL}$ droplet $(62.3 \%, \mathrm{SE}=6.6, n=14)$. A general linear model testing the number of larvae sired by each male with the main effect of syringe volume $(0.01$ or $0.1 \mathrm{~mL})$, the sequence of sample collection (early or late in spawning) blocked by replicate $(n=7)$, the covariate of the total number of larvae sired per syringe, and the interaction of sample volume and sequence revealed no significant effect of sample volume $(P=.14)$, sequence $(P=.24)$, or the interaction of these terms $(P=.72)$. In the smaller-volume droplets, 2 of 14 samples were monogamous, while 1 of the 14 larger water droplets was monogamous. The patterns of dominance comparing the larger $(0.1 \mathrm{~mL})$ samples in 2016 were nearly identical to the value from the same treatment conditions tested in experiment 1 in 2011 (63.7\%,
SE $=4.3$ ). Reducing the water volume of the droplets by an order of magnitude had a nonsignificant effect on the degree of competition within these droplets.

\section{Emergent Results of Considering All Experiments}

Altogether, the likelihood of monogamous versus competitive fertilization was examined at two levels of crowding with four males, two levels of density with two or six males, and one experiment with randomly moving sea urchins with three males. This varied local male density from approximately 2 to $64 / \mathrm{m}^{2}$. In experiments 1 and 4 , samples were collected in the same location over a sequence of time, and no effect of time was noted. Monogamous fertilization was most common when fertilization was high and competing males were distant; otherwise, competitive fertilizations dominated these results. Paternity skew and monogamous fertilization could occur either because sperm from one male outnumber those from other males or because individual spermatozoa from one male have a competitive ad- 
Table 4: Experiment 3, high-density treatment: general linear model of paternity share of each male (number of larvae sired by male) as a function of the main effect of sperm bindin genotype (RG/RG homozygous, RG/GR, and GR/GR), with the distance from the male to the syringe, the fraction of eggs fertilized in a syringe (arcsine transformed), and the total number of larvae sired in a syringe as covariates, plus the interaction of sperm bindin genotype with distance to the syringe

\begin{tabular}{lrcrrr}
\hline Source & df & Type III SS & MS & \multicolumn{1}{c}{$F$} & $\operatorname{Pr}>F$ \\
\hline Sperm bindin & 2 & 48.96 & 24.48 & 3.34 & .0392 \\
Distance & 1 & 49.20 & 49.20 & 6.71 & .0109 \\
Arcfert & 1 & 1.54 & 1.54 & .21 & .6475 \\
Total larvae & 1 & 7.48 & 7.48 & 1.02 & .3147 \\
Sperm bindin $\times$ distance & 2 & 37.60 & 18.80 & 2.56 & .0817 \\
Error & 105 & 769.57 & 7.33 & & \\
$\quad$ Corrected total & 112 & 865.73 & & & \\
\hline
\end{tabular}

Note: There was no significant effect of these factors at the low-density treatment. Sums of squares (SS) and mean squares (MS) are reported.

vantage such as gamete affinity, swimming ability, or chemotactic responsiveness. The winning male garnered a higher paternity share when overall fertilization in the syringe was high in both the first experiment, in the reduced crowding treatment, and in the second experiment, which in general had lower levels of crowding. Sperm bindin genotype significantly influenced paternity when spawning density and the number of males was high and the paternity share among males was more even (fig. 5). In every case where sperm bindin genotype was significant, the higher-compatibility RG protein, as determined from prior experiments (Levitan 2012), garnered higher paternity. When paternity of the winning males was near or above $70 \%$ in a syringe, sperm bindin genotype was not significant. These results suggest that variation in gametic compatibility is likely to be detected when sperm availability is fairly even among males and that when sperm from one male overwhelms others it can swamp the effect of compatibility. Across all experiments, 23 syringes were completely monogamous. Ten of these syringes were fertilized by RG homozygous males (43\%). Overall in these experiments, the genotype frequency of RG homozygous males was 37\%. A Fisher's exact test found no significant skew of genotype with the likelihood of a monogamous syringe $(P=.47)$; when a syringe was completely monopolized by a male, the winner was more dependent on genotype frequency than genotype compatibility.

These results suggest that while paternity skew in these syringes can be influenced by gametic compatibility, monogamous fertilization is more likely caused by a skew in sperm availability. When sperm are well mixed among males, direct gamete competition is possible and can be influenced by gametic compatibility. When sperm are not well mixed, the first-arriving sperm fertilizes eggs and less compatible gametes have the opportunity to succeed. This provides an opportunity for low-affinity males to produce more zygotes under polyspermic conditions. This does not imply that gamete recognition protein genotype does not influence the probability of fertilization and zygote production at lower densities or lower levels of competition, only that fair (near equal sperm numbers) direct competition is less likely in these conditions. Higher-compatibility proteins will always make it more likely that sperm collisions will result in fertilization, and conversely, lower-compatibility pro-

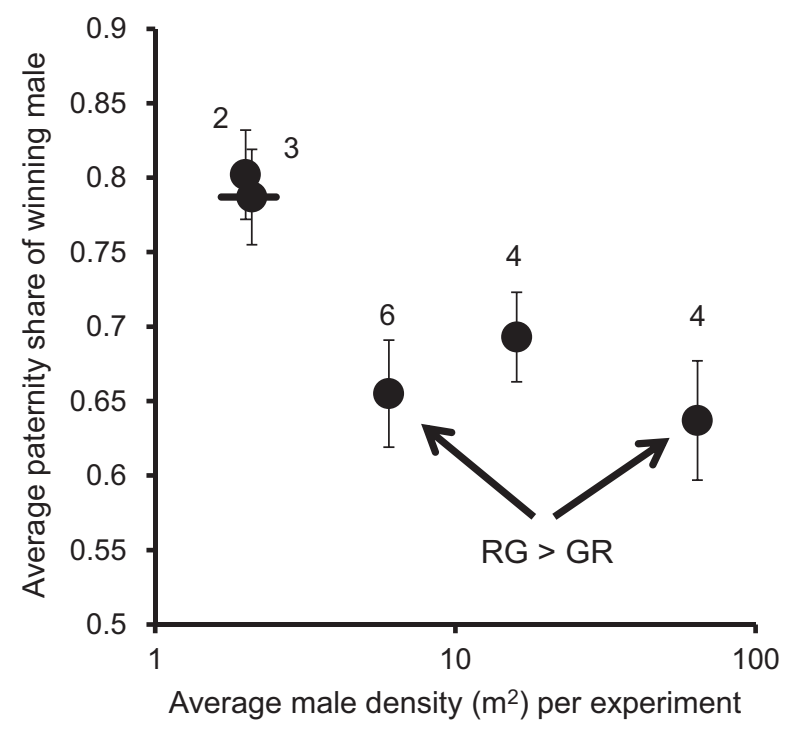

Figure 5: Summary of all experiments as a function of male density, average paternity share (SE), and number of spawning males (reported above each mean). Only in experiment 2 (randomly moving sea urchins) was there variance in density (horizontal SE). Two experiments found a significant effect of sperm bindin genotype (arrows). In both cases, the direction of significance was the same as noted in prior studies (Levitan 2012); RG genotypes outcompete GR genotypes. Sperm bindin genotype was significant at high densities, high number of males, and reduced paternity dominance. In other cases, differences in sperm numbers among males likely swamp paternity dominance and obscured the effect of genotype. 

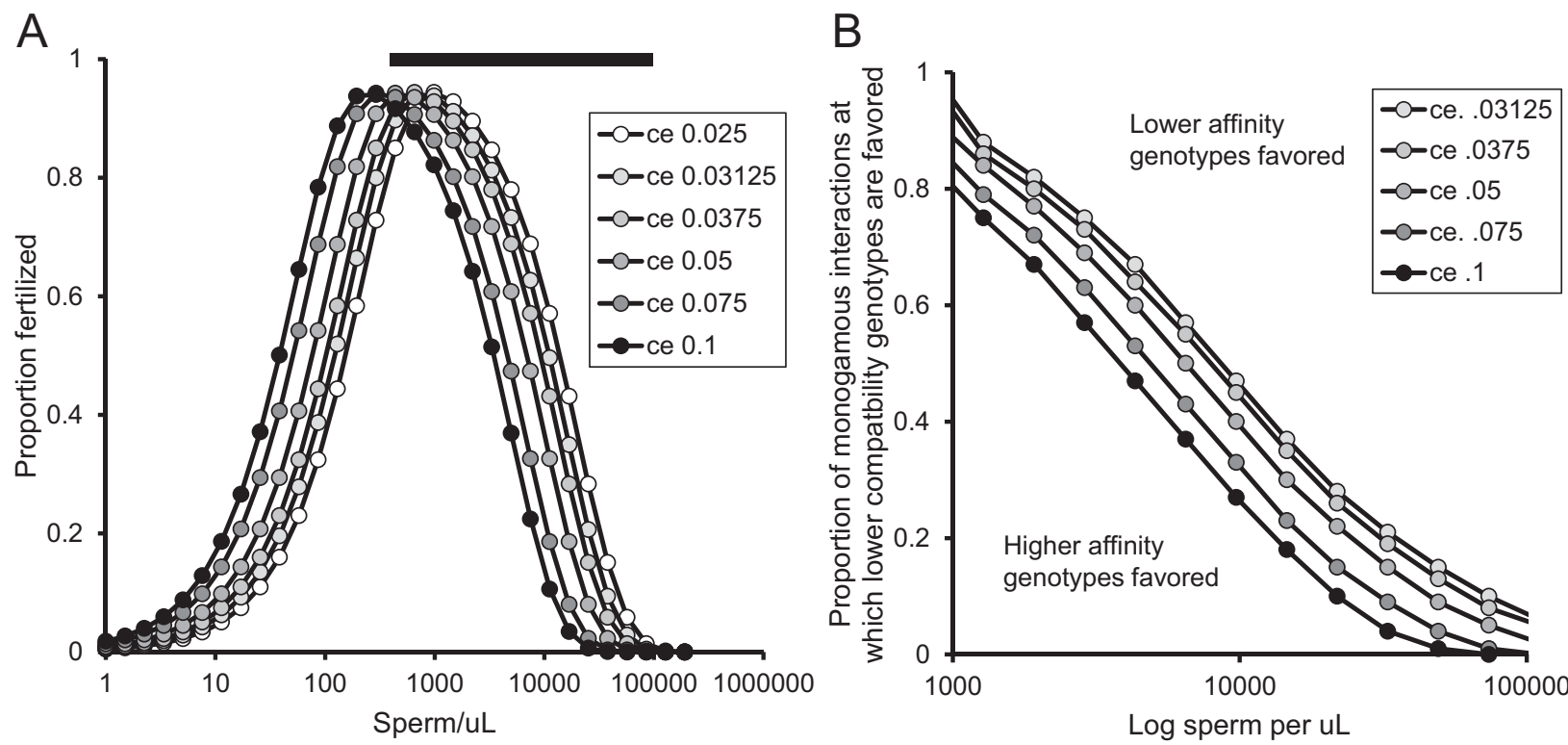

Figure 6: Simulation model of the degree of monogamous fertilizations needed for lower-affinity sperm to have higher fitness than higheraffinity sperm. A, Fertilization curves as a function of gamete affinities (ce $=$ proportion of collisions that result in successful fertilization and development) and parameter values cited in the text, using Styan's (1998) fertilization kinetics model. The black bar indicates range of sperm concentrations in which polyspermy is noted and highlights the range in $B$. $B$, For each value of sperm concentration and the gamete affinity (tested against the lowest affinity 0.025 sperm), the curves represent the proportion of monogamous fertilization events needed to select for low-affinity sperm. Low-affinity sperm is favored as sperm concentration (and the risk of polyspermy) increases, as the proportion of monogamous fertilization events increase and as the compatibility differences between the low-affinity and high-affinity sperm genotypes increases. When polyspermy is not a risk, the high-affinity sperm is always favored.

teins will always make it less likely that sperm collisions will result in polyspermy. Thus, these proteins will always influence zygote production.

\section{Modeling the Competitive Interactions and Selection on Gametic Capability}

The simulation model revealed that sperm genotypes with lower compatibility can have higher fitness under polyspermic conditions if there is some degree of noncompetitive fertilization (fig. 6). The likelihood of lower-affinity sperm being favored increased with the degree of noncompetitive interactions, the sperm concentration, and the difference between the affinities of the two male genotypes. When sperm are limiting or when interactions are always competitive, higher-affinity sperm are always favored. Under moderate conditions of polyspermy, lower-affinity sperm can be favored even with a moderate frequency of noncompetitive fertilization events.

\section{Discussion}

In droplets of seawater that approximate the local sperm environment for single eggs, there was a surprising degree of sperm mixing among multiple males during synchronous group spawning. The potential for direct sperm competi- tion - and thus egg choice - was most common when males were crowded and symmetrically placed around water droplets containing eggs. As the distance and the asymmetry in distance among males increased, and when fertilization in these syringes was high, these droplets increasingly became dominated by sperm from only one male. Complete dominance by single males was only common when competing males were farther than $1 \mathrm{~m}$ from water samples collected near a focal male and when fertilization in the syringes was high. This suggests that when a male has a spatial advantage over other males and a wisp of his sperm strikes eggs, sperm from other males do not have the opportunity to compete for that egg. Finding monogamous fertilization under these conditions is not surprising; what is revealing was the degree to which competitive fertilization was noted under more crowded conditions and when sperm were more dispersed. Although the most common finding in these experiments was competitive fertilization, the experiments were designed to examine cases in which competitive fertilization might occur. Low spawning densities, pair spawning, and asynchronous spawning among males are all conditions that would favor monogamous fertilization.

Altogether these results suggest that both competitive and noncompetitive fertilization events are likely common in the sea, depending on the distribution, abundance, pat- 
terns of synchrony, and sex ratio of spawning individuals. This species of sea urchin is generally found over a range of densities ( $\ll 1 / \mathrm{m}^{2}$ to $32 / \mathrm{m}^{2}$; Bernard and Miller 1973; Rumrill 1987; Bureau 1996), suggesting that these eggs experience both competitive and noncompetitive fertilization events. Other broadcast species or populations within species that spawn more consistently at high levels of crowding (e.g., Sewell and Levitan 1992; Hamel and Mercer 1996; Levitan 2002a) or more generally under dispersed conditions (e.g., Babcock et al. 1992; Brazeau and Lasker 1992; Lasker et al. 1996) might experience consistent patterns of competitive or noncompetitive fertilization. Some broadcast spawning invertebrates are often observed to engage in pair spawning in close proximity or, at times, asynchronously (reviewed in Levitan 1998b). These conditions might reduce the likelihood of competitive fertilization but still expose eggs to very high concentrations of sperm from single males and the risk of polyspermy under noncompetitive conditions.

These experiments did not reveal an effect of time of when the sample was collected on the degree of dominance by a male. Although the expectation is that sperm should continue to dissipate and mix over time, sperm in this and many broadcast spawning species are released as a plume (Denny and Shibata 1989). Sperm dissipating in a plume are replaced by newly released concentrated sperm. Although the concentration and heterogeneity of sperm at a specific location may vary over time, once the plume is established there should be no predictable shift in sperm mixing at a set location (female egg-release point) from a spawning male or population of males. An effect of time would most likely be apparent as males initiate or cease spawning. However, for many broadcast spawning species (Levitan 1998b)and for this species, in particular (Levitan 2002a) — males initiate spawning well before females join in the event and continue to release sperm for the duration of female spawning. This pattern of spawning would tend to reduce a predictable change in the degree of sperm mixing over the time of egg release by females.

Prior experiments on Strongylocentrotus franciscanus indicate that males with RG sperm genotypes outcompete GR genotypes at low population densities in the field and in well-mixed competitive assays in the lab (Levitan 2012). At high spawning densities in which polyspermy is common, males with the GR genotype produce more zygotes, and in lab no-choice experiments, GR genotypes produce more zygotes under polyspermic conditions (Levitan 2012). These results suggest that the success of GR sperm in nature is dependent on conditions in which sperm availability is high and heterogeneously mixed such that GR sperm have the opportunity to arrive and fertilize a proportion of eggs prior to the arrival of RG sperm.

In the current study, males homozygous for the highaffinity RG genotype were able to win paternity share when competing males were close together and when paternity share among males was near equal (suggesting equal sperm contribution). As the distance and asymmetry among males increased, other genotypes with lower affinities were able to garner a majority paternity share and monopolize paternity. There was no evidence that RG males were more likely to completely dominate a syringe and result in monogamous fertilization; when a wisp of sperm hits an egg, monogamous fertilization will result, regardless of genotype. Under polyspermic conditions, as the degree of noncompetitive interactions increase, conditions will increasingly favor a lower affinity sperm type that reduces the risk of polyspermy. This provides a potential explanation for the success of GR males in field experiments conducted under polyspermic conditions (Levitan 2012). What remains unknown - and is being currently explored - is whether GR sperm have evolved to be wimpy to avoid polyspermy or, alternatively, whether this protein has a high affinity to a less common egg receptor in the population.

These results suggest three endpoints in a triangular distribution of gamete interactions. The first endpoint is when sperm are limiting. Under these conditions, high-affinity gametes will always be selected for in both eggs and sperm, and these gametes will be under hard selection to increase zygote production. This type of interaction would result in purifying selection on gamete recognition proteins with the highest affinity toward one another and resisting invasion of lower-affinity gametes (Tomaiuolo and Levitan 2010). The second endpoint represents conditions in which polyspermy is a risk, but males do not directly compete for the fertilization of single eggs. These conditions would favor selection for reduced compatibility in either the sperm or egg recognition loci to lower the risk of polyspermy. This condition could potentially select for wimpy sperm, sperm that are successful because they have a low affinity with available eggs. The last endpoint represents the sexual conflict that occurs when polyspermy is a risk and males directly compete for the fertilization of single eggs. Here, selection should favor invasion of a less compatible egg type, and once this egg type becomes frequent in the population, it allows for the invasion of a complementary sperm type to match this newly common egg receptor. Instead of wimpy sperm, matched sets of compatible sperm-egg recognition proteins should evolve. These matched sets of proteins are predicted to be maintained by frequency-dependent selection that lowers the effective concentration of high-compatible sperm that can induce polyspermy (Tomaiuolo and Levitan 2010).

There are two lines of empirical evidence that support these broad ideas. The first is that among $S$. franciscanus and two congeners, Strongylocentrotus purpuratus and Strongylocentrotus droebachiensis, there are matched gradients in patterns of sperm availability (Levitan 2002a), gamete traits (Levitan 1993, 1998a; Levitan et al. 2007), and sperm bindin protein diversity. On the northwest coast of North America, 
S. purpuratus has the most clumped distribution-eggs that require the highest sperm concentration to achieve fertilization but are the most resistant to polyspermy - and has three common nonsynonymous sperm-binding haplotypes (Levitan and Stapper 2010). The least clumped species, S. droebachiensis, produces eggs that require the lowest sperm concentration to achieve fertilization but are the most susceptible to polyspermy and have only one common sperm bindin protein (Pujolar and Pogson 2011). The current species has intermediate local density, ease of fertilization and polyspermy, and two common sperm bindin proteins (Levitan and Ferrell 2006; Levitan 2012). Although only three species, these data are consistent with the hypothesis that levels of sperm availability influence the evolution of gametic compatibility and degree of protein polymorphism.

The second line of evidence comes from within S. franciscanus. Field studies indicate that $S$. franciscanus densities can vary by several orders of magnitude depending on the presence of predatory sea otters (Watson and Estes 2011). Historic data suggest that sea otters used to be common until human exploitation reduced their numbers to near extinction by the early 1900s (Estes and Duggins 1995). Currently, in the absence of sea otters, sea urchin abundance can be great and lead to the creation of high-density urchin barrens. Correspondingly, the high-affinity RG allele was very common (frequency of 0.8 ) and the GR allele was rare (0.1) several hundred years ago, when $S$. franciscanus was predicted to exist at relatively low densities. Since then, the GR allele has steadily increased in frequency such that at present both alleles are equally common (Levitan 2012). This data on shifting allele frequencies matches the results of how these protein variants perform at high and low densities (Levitan 2012) and suggests that lower-affinity sperm can lead to increased fitness under high-density and polyspermic conditions. Further research will determine whether these sperm protein variants are wimpy or match newly evolved eggreceptor proteins.

\section{The Effectiveness of Conspecific Sperm Precedence as a Reproductive Isolating Mechanism}

Conspecific sperm precedence (CSP), as well as conspecific pollen precedence, is a commonly proposed mechanism of reproductive isolation for a variety of taxa, especially so for groups that release gametes into the environment for fertilization (Howard 1999). Conspecific sperm precedence is thought to be important because there is a high frequency of closely related sympatric species in which crosses in the absence of conspecific sperm yield high levels of fertilization (e.g., Echinoderms - Byrne and Anderson 1994; Cnidarians_-Willis et al. 1997; Annelids_-Pernet 1999). However, for CSP to be effective, sperm from conspecific and heterospecific sperm must collide with eggs in the brief interval in which differential gamete affinities or egg choice can distinguish among sperm. Although higher-affinity conspecific sperm often win in direct competition in the laboratory, CSP is often not perfect and heterospecific sperm often garner a moderate paternity share (Bierne et al. 2002; Geyer and Palumbi 2005; Fogarty et al. 2012b; although for evidence of more effective CSP, see Willis et al. 2006; Fogarty et al. 2012a). The effectiveness of CSP appears to rely in part on the relative abundance of sperm from the competing species (e.g., Geyer and Palumbi 2005; Fogarty et al. 2012b). A test of the likelihood of hybrid fertilization as a function of the relative distances of conspecific and heterospecific males from females releasing eggs into the sea indicated that heterospecific males dominated fertilization when they were closer and more abundant than conspecific males but produced less hybrid fertilizations than predicted solely by nearestneighbor and density differences (Levitan 2002b). This field experiment suggests that CSP can shift fertilizations away from hybridization but cannot eliminate it when eggs are swamped by heterospecific sperm at high densities.

Possible evidence of how CSP can fail with shifts in abundance can be found in the apparent increase in hybridization and introgression in the Caribbean Acroporid corals. The two parental species, Acropora palmata and Acropora cervicornus, underwent a dramatic decrease in abundance during the 1990s caused by a disease outbreak (Aronson and Precht 2001; Precht et al. 2002). Although these species are often found in different microhabitats on reefs, they can be observed in close contact. The hybrid of these two species, initially identified as Acropora prolifera (van Oppen et al. 2000; Vollmer and Palumbi 2002), is absent from the fossil record (Budd et al. 1994) and has only recently been reported at abundances that rival the parental species (Fogarty 2012). Studies of reproductive isolation in these two parental species indicate overlapping spawning times and spatial distribution, the ability of heterospecific sperm to fertilize eggs in no-choice crosses, and evidence for CSP (Fogarty et al. 2012b). No evidence for reduced hybrid fitness was found across life stages from larval survival and settlement through adult survival and growth (Fogarty 2012). A parsimonious explanation for the increase in hybridization and introgression is that lower population densities result in released eggs dispersing for longer periods before encountering sperm and that the first sperm encountered might come from either species (Fogarty et al. 2012b). Hybridization, introgression, and potentially reticulate speciation may be increasingly common among tropical corals that have generally seen a dramatic decrease in abundance due to direct or indirect anthropogenic causes.

\section{The Distinction between Male and Sperm Competition}

Parker (1998) redefined sperm competition from interactions with a single ovum to interactions with a pool of ova 
to better represent the dynamics of competition in external fertilizers. There is ample evidence that male competition and female choice occur in external fertilizers as evidenced by patterns of allocation of ejaculates among spawning events as a function of mating opportunities and how this can generate sexual conflict over fertilization rates (Warner et al. 1995), the consequences of the timing of gamete release between males and females to enhance female success and male competitive ability (Levitan 2005; Lotterhos and Levitan 2010), and female choice in delaying spawning until sperm are available (Levitan 2002a; Reuter and Levitan 2010). The distinction between male competition/ female choice and direct sperm competition/egg choice is how it influences the effectiveness and selection on gametic compatibility and potentially sperm swimming ability (Campbell et al. 2016). Gametic compatibility can be selected to increase or decrease based on sperm availability to optimize zygote production (Levitan 2012) and to avoid hybridization via CSP (Howard 1999). Divergence in reproductive compatibility appears to play a major role in speciation in the sea (Palumbi 1994; Zigler et al. 2005) and the degree of competitive versus monogamous fertilization might play an important role in determining tempo and mode in the evolution of the proteins that determine reproductive compatibility and speciation.

\section{Acknowledgments}

I thank K. Lotterhos, S. Gray, C. Levitan, J. Levitan, K. Levitan, J. Moscoso, K. Olsen, and the 2012 Bamfield Marine Sciences Centre science diving class for assistance in the field and culturing larvae and K. Aranow, R. Buchwalter, and Y. Hao for molecular work. This work was benefited by discussions with E. Kosman, J. Moscoso, K. Olsen, and J. Travis. The fieldwork was conducted at the Bamfield Marine Sciences Centre. This research was supported by the National Science Foundation (DEB 0822626 and DEB 1354272).

\section{Literature Cited}

Andersson, M. A. 1994. Sexual selection. Princeton University Press, Princeton, NJ.

Aronson, R. B., and W. F. Precht. 2001. White-band disease and the changing face of Caribbean coral reefs. Hydrobiologia 460:25-38.

Babcock, R., C. Mundy, J. Keesing, and J. Oliver. 1992. Predictable and unpredictable spawning events - in situ behavioral data from free-spawning coral-reef invertebrates. Invertebrate Reproduction and Development 22:213-228.

Bernard, F. R., and D. C. Miller. 1973. Morphometric data for a preliminary investigation on the red sea urchin resources of British Columbia (Strongylocentrotus franciscanus Ag.). Fisheries Research Board of Canada, Manuscript Report Series 1256. Pacific Biological Station, Nanaimo, BC.
Bierne, N., P. David, P. Boudry, and F. Bonhomme. 2002. Assortative fertilization and selection at the larval stage in the mussels Mytilus edulis and M. galloprovincialis. Evolution 56:292-298.

Birkhead, T. R. 1998. Sperm competition in birds: mechanisms and function. Pages 579-622 in T. Birkhead and A. Møller, eds. Sperm competition and sexual selection. Academic Press, San Diego, CA.

Birkhead, T. R., and A. P. Møller. 1992. Sperm competition in birds: evolutionary causes and consequences. Academic Press, London. . 1998. Sperm competition and sexual selection. Academic Press, San Diego, CA.

Brazeau, D. A., and H. R. Lasker. 1992. Reproductive success in the Caribbean octocoral Briareum asbestinium. Marine Biology 114:157-163.

Budd, A. F., T. A. Stemann, and K. G. Johnson. 1994. Stratigraphic distributions of genera and species of neogene to recent Caribbean reef corals. Journal of Paleontology 68:951-977.

Burczyk, J., and D. Prat. 1997. Male reproductive success in Pseudotsuga menziesii (Mirb.) Franco: the effects of spatial structure and flowering characteristics. Heredity 79:638-647.

Bureau, D. 1996. Relationship between feeding, reproductive condition, jaw size and density in the red sea urchin, Strongylocentrotus franciscanus. MS thesis. Simon Fraser University, Vancouver.

Byrne, M., and M. J. Anderson 1994. Hybridization of sympatric Patirella species (Echinodermata: Asteroidea) in New South Wales. Evolution 48:564-576.

Campbell, A. L., D. R. Levitan, D. J. Hosken, and C. Lewis. 2016. Ocean acidification changes the male fitness landscape. Scientific Reports 6:31250.

Coffroth, M. A., and H. R. Lasker. 1998. Larval paternity and male reproductive success of a broadcast-spawning gorgonian, Plexaura kuna. Marine Biology 131:329-337.

Crimaldi, J. P. 2012. The role of structured stirring and mixing on gamete dispersal and aggregation in broadcast spawning. Lournal of Experimental Biology 215:1031-1039.

Darwin, C. 1871. The descent of man and selection in relation to sex. J. Murray, London.

Denny, M. W., and M. F. Shibata. 1989. Consequences of surf-zone turbulence for settlement and external fertilization. American Naturalist 134:859-889.

Dunn, P. O., L. A. Whittingham, and T. E. Pitcher. 2001. Mating systems, sperm competition, and the evolution of sexual dimorphism in birds. Evolution 55:161-175.

Eberhard, W. G. 1998. Female roles in sperm competition. Pages 91116 in T. Birkhead and A. Møller, eds. Sperm competition and sexual selection. Academic Press, San Diego, CA.

Estes, J. A., and D. O. Duggins. 1995. Sea otters and kelp forests in Alaska: generality and variation in a community ecological paradigm. Ecological Monographs 65:75-100.

Farley, G. S., and D. R. Levitan. 2001. The role of jelly coats in sperm-egg encounters, fertilization success, and selection on egg size in echinoids. American Naturalist 157:626-236.

Fogarty, N. D. 2012. Caribbean acroporid coral hybrids are viable across life history stages. Marine Ecology Progress Series 446:145-159.

Fogarty, N. D., M. Lowenberg, M. N. Ojima, N. Knowlton, and D. R. Levitan. 2012a. Asymmetric conspecific sperm precedence in relation to spawning times in the Montastraea annularis species complex (Cnidaria: Scleractinia). Lournal of Evolutionary Biology 25: 2481-2488.

Fogarty, N. D., S. V. Vollmer, and D. R. Levitan. 2012b. Weak prezygotic isolating mechanisms in threatened Caribbean Acropora corals. PLoS ONE 7:e30486. 
Gage, M. J. G., and E. H. Morrow. 2003. Experimental evidence for the evolution of numerous, tiny sperm via sperm competition. Current Biology 13:754-757.

Gavrilets, S. 2000. Rapid evolution of reproductive barriers driven by sexual conflict. Nature 403:886-889.

Geyer, L. B., and S. R. Palumbi. 2005. Conspecific sperm precedence in two species of tropical sea urchins. Evolution 59:97-105.

Hamel, J.-F., and A. Mercier. 1996. Gamete dispersion and fertilisation success of the sea cucumber Cucumaria frondosa. SPC Bechede-mer Information Bulletin 8:34-40.

Haygood, R. 2004. Sexual conflict and protein polymorphism. Evolution 58:1414-1423.

Howard, D. J. 1999. Conspecific sperm and pollen precedence and speciation. Annual Review of Ecology and Systematics 30:109-132.

Kalinowski, S. T., M. L. Taper, and T. C. Marshall. 2007. Revising how the computer program Cervus accommodates genotyping error increases success in paternity assignment. Molecular Ecology 16:1099-1106.

Lasker, H. R., D. A. Brazeau, J. Calderon, M. A. Coffroth, R. Comia, and K. Kim. 1996. In situ rates of fertilization among broadcast spawning gorgonian corals. Biological Bulletin 190:45-55.

Levitan, D. R. 1993. The importance of sperm limitation to the evolution of egg size in marine invertebrates. American Naturalist 141:517-536.

_ 1998a. Does Bateman's principle apply to broadcast-spawning organisms? egg traits influence in situ fertilization rates among congeneric sea urchins. Evolution 52:1043-1056.

. 1998b. Sperm limitation, sperm competition and sexual selection in external fertilizers. Pages 175-217 in T. Birkhead and A. Møller, eds. Sperm competition and sexual selection. Academic Press, San Diego, CA

2000. Sperm velocity and endurance trade-off and influence fertilization in the sea urchin Lytechinus variegatus. Proceedings of the Roval Societv B 267:531-534.

. 2002a. Density-dependent selection on gamete traits in three congeneric sea urchins. Ecology 83:464-479.

2002b. The relationship between conspecific fertilization success and reproductive isolation among three congeneric sea urchins. Evolution 56:1599-1609.

2004. Density-dependent sexual selection in external fertilizers: variances in male and female reproductive success along the continuum from sperm limitation to sexual conflict in the sea urchin Strongylocentrotus franciscanus. American Naturalist 164:298309.

2005. Sex-specific spawning behavior and its consequences in an external fertilizer. American Naturalist 165:682-694.

- 2012. Contemporary evolution of sea urchin gameterecognition proteins: experimental evidence of density-dependent gamete performance predicts shifts in allele frequencies over time. Evolution 66:1722-1736.

-2017. Data from: Do sperm really compete and do eggs ever have a choice? adult distribution and gamete mixing influence sexual selection, sexual conflict, and the evolution of gamete recognition proteins in the sea. American Naturalist, Dryad Digital Repository, http://dx.doi.org/10.5061/dryad.c57rf.

Levitan, D. R., and D. L. Ferrell. 2006. Selection on gamete recognition proteins depends on sex, density and genotype frequency. Science 312:267-269.

Levitan, D. R., M. A. Sewell, and F. S. Chia. 1991. Kinetics of fertilization in the sea urchin Strongylocentrotus franciscanus: interac- tion of gamete dilution, age, and contact time. Biological Bulletin 181:371-378.

Levitan, D. R., and A. P. Stapper. 2010. Simultaneous positive and negative frequency dependent selection on sperm binding, a gamete recognition protein in the sea urchin Strongylocentrotus purpuratus. Evolution 64:785-797.

Levitan, D. R., C. P. TerHorst, and N. D. Fogarty. 2007. The risk of polyspermy in three congeneric sea urchins and its implications for gametic incompatibility and reproductive isolation. Evolution 61:2007-2014.

Lotterhos, K. E., and D. R. Levitan. 2010. Gamete release and spawning behavior in broadcast spawning marine invertebrates. Pages 99-120 in J. Leonard, ed. The evolution of primary sexual characters. Oxford University Press, Oxford.

Marshall, D. J., C. A. Styan, and M. J. Keough. 2002. Sperm environment affects offspring quality in broadcast spawning marine invertebrates. Ecological Letters 5:173-176.

McKinney, F., K. M. Cheng, and D. J. Bruggers. 1984. Sperm competition in apparently monogamous birds. Pages 523-545 in R. I. Smith, ed. Sperm competition and the evolution of animal mating systems. Academic Press, Orlando, FL.

Millar, R. B., and M. J. Anderson. 2003. The kinetics of monospermic and polyspermic fertilization in free-spawning marine invertebrates. Journal of Theoretical Biology 224:79-85.

Palumbi, S. R. 1994. Genetic divergence, reproductive isolation, and marine speciation. Annual Review of Ecology and Evolution 25:547-572. . 1999. All males are not created equal: fertility differences depend on gamete recognition polymorphisms in sea urchins. Proceedings of the National Academv of Sciences of the USA 96: 12632-12637.

Parker, G. A. 1970. Sperm competition and its evolutionary consequences in the insects. Biological Review 45:525-567.

. 1998. Sperm competition and the evolution of ejaculates: towards a theory base. Pages 3-54 in T. Birkhead and A. Møller, eds. Sperm competition and sexual selection. Academic Press, San Diego, CA.

Pernet, B. 1999. Gamete interactions and genetic differentiation among three sympatric polychaetes. Evolution 53:435-446.

Podolsky, R. D. 2002. Fertilization ecology of egg coats: physical versus chemical contributions to fertilization success of free-spawned eggs. Journal of Experimental Biology 205:1657-1668.

Precht, W. F., A. W. Bruckner, R. B. Aronson, and R. J. Bruckner. 2002. Endangered Acroporid corals of the Caribbean. Coral Reefs 21:41-42.

Pujolar, J. M., and G. H. Pogson. 2011. Positive selection in gamete recognition proteins of Strongylocentrotus sea urchins. Molecular Ecology 23:4968-4982.

Reuter, K. E., and D. R. Levitan. 2010. Influence of sperm and phytoplankton on spawning in the echinoid Lytechinus variegatus. Biological Bulletin 219:198-206.

Riffell, J. A., P. K. Frug, and R. K. Zimmer. 2004. The ecology and evolutionary consequences of sperm chemoattraction. Proceedings of the National Academv of Sciences of the USA 101:4501-4506.

Rumrill, S. S. 1987. Predation upon echinoderm embryos and larvae. PhD diss. University of Alberta, Edmonton.

Sewell, M. A., and D. R. Levitan. 1992. Fertilization success in a natural spawning of the dendrochirote sea cucumber Cucumaria miniata. Bulletin of Marine Science 51:161-166.

Simmons, L. W., and M. T. Siva-Jothy. 1998. Sperm competition in insects: mechanisms and the potential for selection. Pages 341- 
434 in T. Birkhead and A. Møller, eds. Sperm competition and sexual selection. Academic Press, San Diego, CA.

Styan, C. A. 1998. Polyspermy, egg size, and the fertilization kinetics of free-spawning marine invertebrates. American Naturalist 152 290-297.

Swanson, W. J., and V. D. Vacquier. 2002. Reproductive protein evolution. Annual Review of Ecology and Systematics 33:161-179.

Thornhill, R., and J. Alcock. 1983. The evolution of insect mating systems. Harvard University Press, Cambridge, MA.

Tomaiuolo, M., and D. R. Levitan. 2010. Modeling how reproductive ecology can drive protein diversification and result in linkagedisequilibrium between sperm and egg proteins. American Naturalist 176:12-25.

Tourmente, M., M. Gomendio, and E. R. S. Roldan. 2011. Sperm competition and the evolution of sperm design in mammals. BMC Evolutionary Biology 11:12.

van Oppen, M. J. H., B. L. Willis, J. A. van Vugt, and D. J. Miller. 2000 Examination of species boundaries in the Acropora cervicornis group (Scleractinia, Cnidaria) using nuclear DNA sequence analyses. Molecular Ecology 9:1363-1373.

Vollmer, S. V., and S. R. Palumbi. 2002 Hybridization and the evolution of reef coral diversity. Science 296:2023-2025.
Wallace, B. 1975. Hard and soft selection revisited. Evolution 29: 465-473.

Warner, R. R., D. Y. Shapiro, A. Marcanato, and C. W. Peterson. 1995. Sexual conflict: males with the higher mating success convey the lowest fertilization benefits to females. Proceedings of the Roval Societv B 262:135-139.

Watson, J., and J. A. Estes. 2011. Stability, resilience, and phase shifts in rocky subtidal communities along the west coast of Vancouver Island, Canada. Ecological Monographs 81:215-239.

Willis, B. L., R. Babcock, P. Harrison, and C. Wallace. 1997. Experimental hybridization and breeding incompatibilities within mating systems of mass spawning corals. Coral Reefs 16:S53-S65.

Willis, B. L., M. J. H. van Oppen, D. J. Miller, S. V. Vollmer, and D. J. Ayre. 2006. The role of hybridization in the evolution of reef corals. Annual Review of Ecology, Evolution, and Systematics 37:489-517.

Zigler, K. S., M. A. McCartney, D. R. Levitan, and H. A. Lessios. 2005. Sea urchin binding divergence predicts gamete compatibility. Evolution 59:2399-2404

Associate Editor: Stephen R. Proulx Editor: Yannis Michalakis

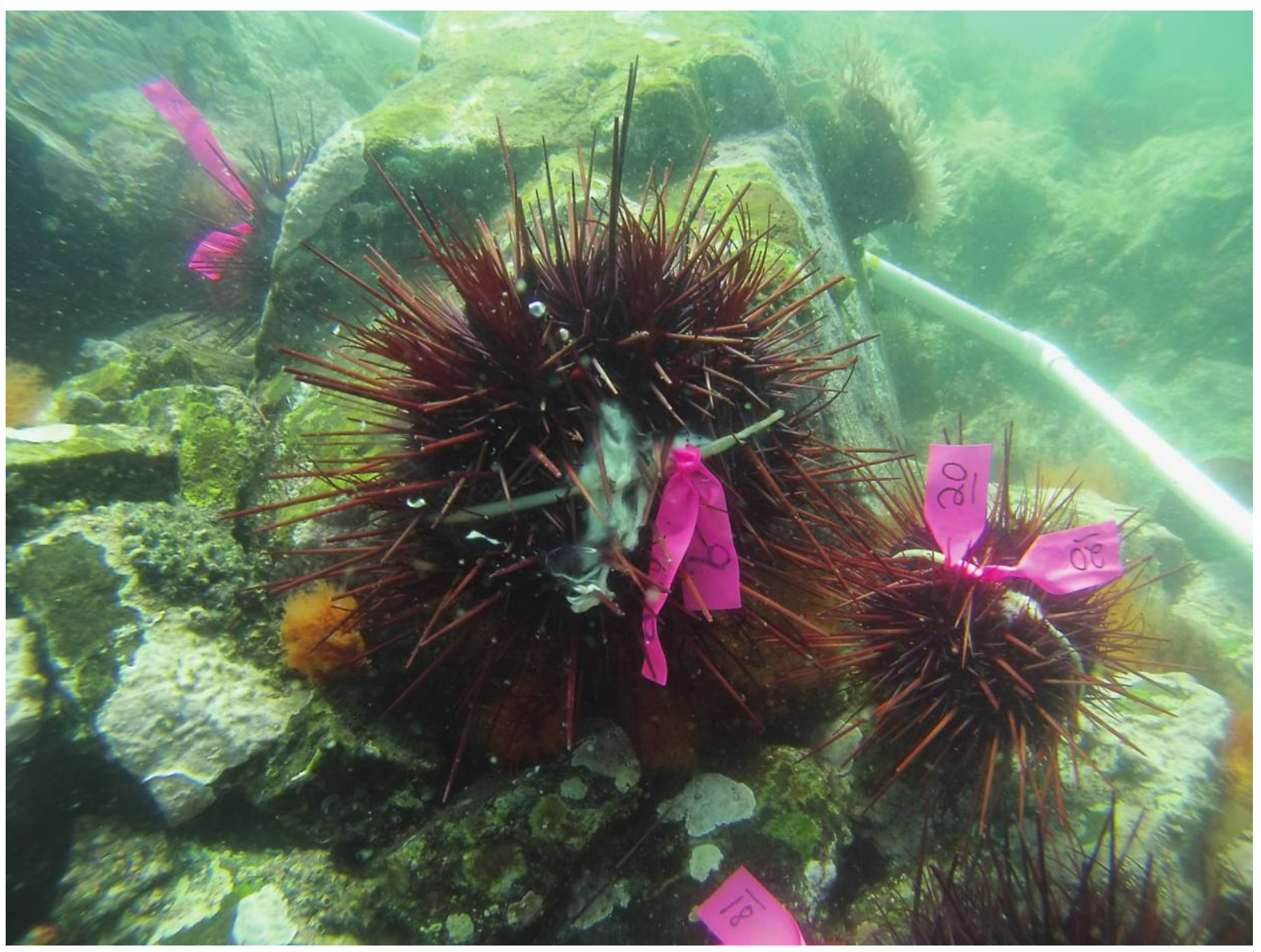

Male sea urchins spawning off the Pacific coast of Canada. Individuals are tagged, mapped, and genotyped for parentage analysis and sequencing of their sperm proteins. Photo credit: Kevin Olsen. 